\title{
Antibiotic prescription for febrile outpatients: a health facility-based secondary data analysis for the Greater Accra region of Ghana
}

\author{
Michael Mireku Opoku', Harriet Affran Bonful ${ }^{1 *}$ (1) and Kwadwo Ansah Koram²
}

\begin{abstract}
Background: Misguided prescription of antibiotics is an important contributor towards the emergence and spread of antibiotic resistance. The absence of effective interventions to control antibiotic use leads to increased consumption beyond the needed requirements. Antibiotic stewardship interventions must be appropriately targeted and assessed to enhance the controlled use of antibiotics. The objective of this study was to determine the factors associated with antibiotic prescription to febrile outpatients who seek care in health facilities within the Greater Accra region of Ghana.
\end{abstract}

Methods: Secondary data obtained from the medical records of 2519 febrile outpatients, consecutively sampled at the outpatient department of 6 health facilities in 3 municipalities during the baseline survey of a quasi-experiment in 2015 was used. The primary outcome was prescription of any antibiotic. Independent variables included patients' demographics, symptoms, laboratory investigations (blood film microscopy, malaria rapid diagnostic test, full blood count, urine and stool routine examinations), diagnoses, and prescribers' demographics. Crude and adjusted logistic regression analyses were used to determine the factors associated with antibiotic prescription.

Results: The prevalence of antibiotic prescription was 70.1\% (95\% Cl: 67.7-72.4). Prescribers with more years of practice ( $>5$ years) were more likely to prescribe antibiotics compared to those with less than 3 years of practice $(p<0.001)$. Integrated Management of Neonatal and Childhood Illnesses (IMNCI) training was associated with a 2.3 ( $95 \%$ Cl: $1.54,3.53, p<0.001$ ) fold odds of antibiotic prescribing. Patients aged 5 years or more were $60 \%$ less likely to receive antibiotics compared with those under 5 years ( $\mathrm{AOR}=0.40,95 \% \mathrm{Cl}: 0.32,0.51 ; p<0.001$ ). Patients referred for laboratory investigations were $29 \%$ less likely to be prescribed antibiotics than those not referred. The presence of cough as a presenting symptom was associated with a $3.5(95 \% \mathrm{Cl}: 2.54,4.92)$ fold odds of antibiotic prescription. Conclusion: Prescription of antibiotics to febrile outpatients was high. Promoting laboratory testing can potentially reduce irrational antibiotic prescription. Prescribing antibiotics for children under five and the prescribing practices of prescribers with longer years of practice should be targeted with interventions to reduce high use of antibiotics.

Keywords: Antibiotic prescription, Febrile, Facility-based, Ghana

\footnotetext{
*Correspondence: habonful@ug.edu.gh

'Department of Epidemiology and Disease Control, School of Public Health, University of Ghana, Legon, Ghana

Full list of author information is available at the end of the article
}

C C The Author(s). 2020 Open Access This article is licensed under a Creative Commons Attribution 4.0 International License, which permits use, sharing, adaptation, distribution and reproduction in any medium or format, as long as you give appropriate credit to the original author(s) and the source, provide a link to the Creative Commons licence, and indicate if changes were made. The images or other third party material in this article are included in the article's Creative Commons licence, unless indicated otherwise in a credit line to the material. If material is not included in the article's Creative Commons licence and your intended use is not permitted by statutory regulation or exceeds the permitted use, you will need to obtain permission directly from the copyright holder. To view a copy of this licence, visit http://creativecommons.org/licenses/by/4.0/ The Creative Commons Public Domain Dedication waiver (http://creativecommons.org/publicdomain/zero/1.0/) applies to the data made available in this article, unless otherwise stated in a credit line to the data. 


\section{Background}

Antibiotic resistance is a major global health challenge. Frequent or misguided consumption of antibiotics are critically important facilitators of the emergence and spread of antibiotic resistance [1, 2]. Higher consumption is not only associated with antibiotic resistance at the individual level but also at the community, national and regional levels, with implications for all patients [2]. A study of the global consumption pattern of antibiotics found that antibiotic consumption increased by $65 \%$ between 2000 and 2015 [3]. Consequently, antibiotic resistance is on an upward trajectory [4]. Studies have shown that an increase in antibiotic prescription correlated with an increase in antibiotic resistance $[5,6]$. In view of these, the estimate that antibiotic consumption will increase out of proportion to requirements by 2030 if no new policy interventions are implemented is worrying [3].

Developing countries contribute disproportionately more to the increasing trend of antibiotic consumption than developed countries [3, 4, 7]. Owing to the poor availability of data, antibiotic use in these countries is not optimally understood [8]. In African communities, high and inappropriate use of antibiotics have been shown to be widespread $[9,10]$. The prevalence of antibiotic prescription in selected hospitals across Africa has been estimated to be $50 \%$ [9]. This claims the highest out of all the WHO regions. A comparable point prevalence $(51.4 \%)$ was determined by an antibiotic use survey at a teaching hospital in Ghana [11]. Inappropriate prescription of antibiotics has also been established among prescribers in other parts of Ghana [12, 13]. The phenomenon is driven by: patients' demands, poor quality laboratory services, pressure from pharmaceutical companies' promotional activities, and health worker factors such as non-adherence, and lack of knowledge and lack of access to institutional guidelines [14-16].

Interventions which have been introduced to reduce irrational prescription of antibiotics in Ghana include the Standard Treatment Guidelines (STG) and Essential Medicines List (EML), provision of training and supervision for health care providers and mass education of the public [17]. To ensure rational use of antibiotics and delay potential development of antimicrobial resistance, the Ghana National Policy on antimicrobial use and resistance has been introduced [18].

For these interventions to be successful, the determinants of the prevailing undesirable patterns of antibiotic use need to be identified and appropriately targeted in local antibiotic stewardship education [19]. In the long run, these activities should lead to a reduction in the rate of emergence of bacterial resistance, hospital visits, medical costs and the incidence of side effects [20, 21]. The knowledge gained will be key to informing the policy changes necessary for reversing the increasing trend of antibiotic consumption at all levels.

To these ends, the objective of this study was to determine the factors associated with prescription of antibiotics for febrile outpatients who sought care in health facilities within the Greater Accra region of Ghana using data from the last quarter of 2015.

\section{Methods}

Data for the current study was obtained from the baseline survey of a quasi-experimental study, which sought to develop and assess the effectiveness of a one-way text messaging intervention on health providers' adherence to malaria case management guidelines [22]. The survey was conducted in 6 health facilities, 2 in each of the 3 municipalities: Ga South, La Dade-Kotopon and LaNkwantanang Madina, in the Greater Accra region.

In the Ghanaian health care delivery system, patients' medical records are usually captured in booklets and cards called folders. They are kept on shelves and retrieved manually at every visit by a patient to the health facility. Some health facilities store patient medical information using electronic folders. With the exception of Pentecost Hospital, which operates an electronic patient folder management system, the remaining 5 health facilities (Police, Ga South Municipal and La General Hospitals, Kekele Polyclinic, and Ngleshie Amanfrom Health Centre use the manual system of management of medical information.

A data extraction tool was used to obtain information from the folders of 2519 febrile outpatients in the 6 health facilities between October and December 2015.

It captured information on demographic characteristics, National Health Insurance Scheme (NHIS) membership, presenting symptoms, laboratory investigations requested (including blood film microscopy or malaria rapid diagnostic test, full blood count (FBC), stool examination for parasitic infections (stool routine examination) and simple urine examination for protein and haematuria (urine routine examination), diagnoses and prescribed drugs including information on the dosage regimen. Further to that, the 82 prescribers who saw the outpatients were interviewed using a structured questionnaire. This questionnaire captured information on prescribers' demographics, exposure to in-service training on malaria case management (MCM) and integrated management of neonatal and childhood illnesses (IMNCI), access to guidelines or other reference materials on MCM, and exposure to supervision in the past 6 months.

Febrile outpatients included in this study were neither detained for observation nor admitted on the ward but treated on ambulatory basis at the outpatient 
departments. Based on recommendations by the WHO and the STG, being febrile was defined as having a recorded body temperature of $37.5^{\circ} \mathrm{C}$ or higher and/or having fever recorded in clinical notes on a survey day $[23,24]$. Records of febrile outpatients who were pregnant or who attended for review of previous illnesses were excluded.

\section{Sampling}

Total enumerative sampling was used to select folders of all eligible febrile outpatients daily until the sample size allocated to each municipality was reached. Details on the data extraction tools and detailed methodology of the baseline survey has been published elsewhere [22]

\section{Data analysis}

The entire data obtained from the primary study was validated and analysed using Stata Version 14 [25]. For the purposes of this study, diagnoses of interest were defined as all diagnoses which had a prevalence of at least $5 \%$ in the database. Those below $5 \%$ were excluded because their frequencies were low, yet, they were so many to have led to overfitting the data, with subsequent unreliable estimates. Some of the diagnoses that were excluded include hypertension, bacteraemia, nephritis, mastitis, and diabetes mellitus. The prevalence of bacteremia and mastitis, for example, were $2.9 \%(N=$ $2519)$ and $0.3 \%(N=2519)$, respectively.

The outcome variable, prescription of antibiotics, was derived based on whether or not at least 1 antibiotic was prescribed for the patient. A prescribed medicine was considered an antibiotic if it was so classified by the WHO Anatomical Therapeutic Chemical classification, J01 (Antibacterials for systemic use) and P01AB (nitroimidazole derivatives) [26].

The distribution of categorical variables such as sex, the presenting symptoms, the diagnoses and laboratory investigations were assessed using frequencies. For continuous variables such as age, normality was assessed using histograms. To adjust for clustering, unique identifiers for each patient folder and for the municipalities were chosen as primary sampling units and stratum identifiers, respectively. Univariable logistic regression analyses were used to estimate unadjusted odds ratios for all the independent variables. The variables which were significantly associated with antibiotic prescribing $(p<0.05)$ were used to fit a multivariable logistic regression model. Although sex of patient was not significant in the crude analysis it was included in the adjusted model because it was considered a potential confounder. The factors in the adjusted model were checked for multicollinearity using the "Collin" command in Stata 14. A variance inflation factor (VIF) of less than 10 was considered acceptable. There were $1.2 \%$ of missing values for patient age and $1.5 \%$ for years of practice, totalling $2.7 \%$ of the 2519 observations. This was anticipated and adjusted for in the determination of the sample size in the original study. Missing data was addressed using listwise deletion. Adjusted Wald test was used to determine the significance of multilevel categorical variables in the model. Cluster-Robust standard errors were estimated for all models. Statistical significance was set at $p<0.05$.

\section{Ethical considerations}

Ethical approval for the primary study was given by the Ethics Review Committee of the Ghana Health Service. Permission was further sought from the Greater Accra Regional Health Administration, the municipal health directorates of the study sites and the management of health facilities and prescribers. Informed written consent were obtained from all the prescribers who saw the patients whose records were used.

\section{Results}

A total of 2519 valid records of patients, who had received care at the selected health facilities in Accra, were used for the study. They were unique singular encounters with patients. Patient and facility level descriptive characteristics are presented (Table 1). Of patients who received antibiotics, 4 out of 10 were aged above 5 years. It must be noted that $1.2 \%$ of the folders did not have age recorded in them. The proportion of females who received antibiotics was $51.9 \%$. $57.6 \%$ of patients were registered with the main social health insurance scheme in Ghana, the national health insurance scheme (NHIS) or other schemes.

The distribution of symptoms of the patients by age group is presented (Table 2). A total of 11,953 symptoms were recorded. While headache $(10.5 \%)$ was generally the most frequently reported symptom, nasal congestion (11.6\%), poor appetite (11.2\%), cough (10.3\%) and watery stool $(8.4 \%)$ were more frequently reported among the children under 5 .

Table 3 shows the distribution of diagnoses by age group. On average, $4(10,026 / 2519)$ diagnoses were made per patient. Generally, the predominant diagnosis was acute respiratory tract infection (ARTI) (11.0\%). Among the under 5 age group, this pattern of ARTI being the most frequently diagnosed condition was observed (12.7\%). However, for all the other age groups, malaria was the most frequently diagnosed condition; $10.7 \%, 5-$ 14 years; $11.1 \%$, $15-29$ years; $10.4 \%$, $30-44$ years; $10.4 \%$, $\geq 45$ years.

Table 4 presents a summary of the prescriber-patient interactions regarding antibiotic prescriptions at the health facilities during the period when the records were taken. Overall, the prevalence of antibiotic prescription was 70.1\% (95\% CI: 67.7-72.4\%). Age-group stratified 
Table 1 Facility and patient level descriptive characteristics by antibiotic prescription

\begin{tabular}{|c|c|c|c|c|c|c|}
\hline & \multicolumn{6}{|c|}{ Antibiotic prescription } \\
\hline & \multicolumn{2}{|c|}{ Not Prescribed } & \multicolumn{2}{|c|}{ Prescribed } & \multicolumn{2}{|c|}{ Total, $N=2519$} \\
\hline & $\mathrm{N}$ & $\%^{a}$ & $\mathbf{n}$ & $\%^{\mathbf{b}}$ & $\mathrm{n}$ & $\%^{c}$ \\
\hline \multicolumn{7}{|l|}{ Municipality } \\
\hline \multicolumn{7}{|l|}{ Ga South $(N=811)$} \\
\hline Ga South Municipal Hospital & 148 & 74.7 & 430 & 70.1 & 578 & 71.3 \\
\hline Ngleshie Amanfrom Health Centre & 50 & 25.3 & 183 & 29.9 & 233 & 28.7 \\
\hline \multicolumn{7}{|l|}{ La Dade Kotopon $(N=802)$} \\
\hline La General Hospital & 78 & 35.5 & 215 & 36.9 & 293 & 36.5 \\
\hline Police Hospital & 142 & 64.5 & 367 & 63.1 & 509 & 63.5 \\
\hline \multicolumn{7}{|l|}{ La Nkwantanang Madina $(N=906)$} \\
\hline Kekele Polyclinic & 145 & 43.3 & 71 & 12.4 & 216 & 23.8 \\
\hline Pentecost Hospital & 190 & 56.7 & 500 & 87.6 & 690 & 76.2 \\
\hline \multicolumn{7}{|l|}{ Patient age-group } \\
\hline$<5$ & 186 & 24.7 & 963 & 54.5 & 1149 & 45.6 \\
\hline$\geq 5$ & 552 & 73.3 & 788 & 44.6 & 1340 & 53.2 \\
\hline Unknown & 15 & 2.0 & 15 & 0.9 & 30 & 1.2 \\
\hline \multicolumn{7}{|l|}{ Sex } \\
\hline Male & 343 & 45.6 & 848 & 48.0 & 1191 & 47.3 \\
\hline Female & 410 & 54.4 & 917 & 51.9 & 1327 & 52.7 \\
\hline \multicolumn{7}{|l|}{ Client on NHIS } \\
\hline Yes & 426 & 56.6 & 1026 & 58.1 & 1452 & 57.6 \\
\hline No & 327 & 43.4 & 740 & 41.9 & 1067 & 42.4 \\
\hline
\end{tabular}

ABBREVIATION: NHIS National Health Insurance Scheme; a: Proportion of those who received antibiotics; b: Proportion of those who did not receive antibiotics; c: proportion based on total number seen at the municipal facility

analyses showed that prevalence of antibiotic prescription was $83.8 \%$ (95\% CI: 81.3-86.1) among patients under 5 and $58.8 \%$ (95\% CI: 55.7-61.9) among patients aged 5 years or more. Of the 1766 prescriptions that had antibiotics prescribed, approximately half (49.2\%) were written by physician assistants, $43.9 \%$ by medical doctors and $5.7 \%$ by nurse prescribers. Regarding the number of years they had been practising, $31.4 \%$ of the patients were seen by prescribers who had been practising for less than 3 years, a little over a third (37.7\%) had been

Table 2 Distribution of symptoms by age-group

\begin{tabular}{|c|c|c|c|c|c|c|c|}
\hline \multirow[t]{2}{*}{ Symptoms } & \multicolumn{7}{|c|}{ Age-group in years } \\
\hline & $<5(n=1149)$ & $5-14(n=353)$ & $15-29(n=435)$ & $30-44(n=310)$ & $\geq 45(n=242)$ & Unknown $(n=30)$ & Total $(N=2519)$ \\
\hline Headache & $392(7.3)$ & $215(12.7)$ & $289(13.1)$ & $201(14.3)$ & $150(12.2)$ & $11(12.0)$ & $1258(10.5)$ \\
\hline Poor appetite & $600(11.2)$ & $160(9.4)$ & $159(7.2)$ & $95(6.8)$ & $98(8.0)$ & $8(8.7)$ & $1120(9.4)$ \\
\hline Nasal congestion & $619(11.6)$ & $140(8.2)$ & $128(5.8)$ & $74(5.3)$ & $68(5.5)$ & $3(3.3)$ & $1032(8.6)$ \\
\hline General Body pains & $360(6.7)$ & $130(7.7)$ & $213(9.7)$ & $152(10.9)$ & $134(10.9)$ & $6(6.5)$ & $995(8.3)$ \\
\hline Watery stool & $448(8.4)$ & $126(7.4)$ & $134(6.1)$ & $77(5.5)$ & $74(6.0)$ & $1(1.1)$ & $860(7.2)$ \\
\hline Dizziness & $356(6.7)$ & $119(7.0)$ & $176(8.0)$ & $92(6.6)$ & $94(7.6)$ & $4(4.3)$ & $841(7.0)$ \\
\hline Cough & $548(10.3)$ & $94(5.5)$ & $70(3.2)$ & $57(4.1)$ & $47(3.8)$ & $12(13.0)$ & $828(6.9)$ \\
\hline Fatigue & $364(6.8)$ & $107(6.3)$ & $160(7.3)$ & $88(6.3)$ & $83(6.7)$ & $2(2.2)$ & $804(6.7)$ \\
\hline Dysuria & $366(6.8)$ & $112(6.6)$ & $146(6.6)$ & $80(5.8)$ & $76(6.2)$ & $4(4.3)$ & $784(6.6)$ \\
\hline Nausea & $354(6.6)$ & $105(6.2)$ & $136(6.2)$ & $72(5.2)$ & $79(6.4)$ & $1(1.1)$ & 747 (6.2) \\
\hline Other & $937(17.5)$ & $389(22.9)$ & $588(26.7)$ & $403(29.0)$ & $327(100.0)$ & $40(43.5)$ & $2684(22.5)$ \\
\hline Total & $5344(100.0)$ & $1697(100.0)$ & $2199(100.0)$ & $1391(100.0)$ & $1230(100.0)$ & $92(100.0)$ & $11,953(100.0)$ \\
\hline
\end{tabular}


Table 3 Distribution of diagnoses by age-group

\begin{tabular}{|c|c|c|c|c|c|c|c|}
\hline \multirow[t]{2}{*}{ Diagnoses } & \multicolumn{7}{|c|}{ Age -group in years } \\
\hline & $<5(n=1149)$ & $5-14(n=353)$ & $15-29(n=435)$ & $30-44(n=310)$ & $\geq 45(n=242)$ & Unknown $(2=30)$ & Total $(N=2519)$ \\
\hline ARTI & $618(12.7)$ & $136(9.4)$ & $157(9.5)$ & $101(9.8)$ & $85(8.6)$ & $9(22.0)$ & $1106(11.0)$ \\
\hline Malaria & $423(8.7)$ & $156(10.7)$ & $184(11.1)$ & $148(10.4)$ & $103(10.4)$ & 15 (36.6) & $1029(10.3)$ \\
\hline UTI & $401(8.3)$ & $119(8.2)$ & $143(8.6)$ & $81(7.8)$ & $71(7.2)$ & $4(9.8)$ & $819(8.2)$ \\
\hline Typhoid fever & $357(7.4)$ & $113(7.8)$ & $138(8.3)$ & $84(8.1)$ & $79(7.4)$ & $1(2.4)$ & $772(7.7)$ \\
\hline Enteritis & $371(7.7)$ & $122(8.4)$ & $127(7.7)$ & $72(7.0)$ & $73(7.4)$ & $1(2.4)$ & 766 (7.6) \\
\hline Pneumonia & $379(7.8)$ & $103(7.1)$ & $117(7.1)$ & $65(6.3)$ & $68(6.8)$ & $0(0.0)$ & $732(7.3)$ \\
\hline Ear infection & $387(8.0)$ & $104(7.2)$ & $113(6.8)$ & $59(5.7)$ & $68(6.8)$ & $0(0.0)$ & $731(7.3)$ \\
\hline Tonsilitis & $368(7.6)$ & $114(7.8)$ & $114(6.9)$ & $65(6.3)$ & $65(6.5)$ & $0(0.0)$ & $726(7.2)$ \\
\hline Anaemia & $344(7.1)$ & 109 (7.5) & $122(7.4)$ & $70(6.8)$ & $67(6.7)$ & $3(7.3)$ & $715(7.1)$ \\
\hline Eye infection & $360(7.4)$ & $107(7.4)$ & 109 (6.6) & $60(5.8)$ & $66(6.6)$ & $0(0.0)$ & $702(7.0)$ \\
\hline Others & 841 (17.3) & $271(18.6)$ & $331(20.0)$ & $229(22.1)$ & $248(25.0)$ & $8(19.5)$ & $1928(19.2)$ \\
\hline Totals & $4849(100.0)$ & $1454(100.0)$ & $1655(100.0)$ & $1034(100.0)$ & 993 (100.0) & $41(100.0)$ & $10,026(100.0)$ \\
\hline
\end{tabular}

ABBREVIATION: ARTI Acute Respiratory Tract Infection, UTI Urinary Tract Infection

practising for 3 to 5 years, and $30.9 \%$ had been practising for 6 years or more. The largest proportion of the prescriptions with antibiotics were written by prescribers who had been practising for 3 to 5 years (37.4\%). While $79.4 \%$ of the prescriptions with antibiotics were written by prescribers who had never been trained on integrated management of neonatal and childhood illnesses (IMNCI), $87.9 \%$ of the prescriptions without antibiotics were written by those with no training on IMNCI.

Table 4 Prescriber-patient interactions by antibiotic prescription

\begin{tabular}{|c|c|c|c|c|c|c|}
\hline \multirow{3}{*}{$\begin{array}{l}\text { Prescriber } \\
\text { Characteristic }\end{array}$} & \multicolumn{6}{|c|}{ Antibiotic prescription } \\
\hline & \multicolumn{2}{|c|}{ Not prescribed } & \multicolumn{2}{|c|}{ Prescribed } & \multicolumn{2}{|c|}{ Total, $N=2519$} \\
\hline & $n$ & $\%$ & $n$ & $\%$ & $n$ & $\%$ \\
\hline \multicolumn{7}{|c|}{ Prescriber's Profession } \\
\hline Medical Doctor & 289 & 38.4 & 776 & 43.9 & 1065 & 42.3 \\
\hline Physician Assistant & 432 & 57.4 & 869 & 49.2 & 1301 & 51.6 \\
\hline Nurse prescriber & 24 & 3.2 & 100 & 5.7 & 124 & 4.9 \\
\hline Other & 8 & 1.1 & 21 & 1.2 & 29 & 1.2 \\
\hline Total & 753 & 100.0 & 1766 & 100.0 & 2519 & 100.0 \\
\hline
\end{tabular}

\section{Prescriber's years of practice}

$\begin{array}{lllllll}<3 & 279 & 37.7 & 500 & 28.7 & 779 & 31.4 \\ 3-5 & 284 & 38.4 & 652 & 37.4 & 936 & 37.7 \\ 6-9 & 99 & 13.4 & 289 & 16.6 & 388 & 15.7 \\ \geq 10 & 78 & 10.5 & 300 & 17.2 & 378 & 15.2 \\ \text { Total } & 740 & 100.0 & 1741 & 100.0 & 2481 & 100.0\end{array}$

Ever trained on IMNCI

\begin{tabular}{lllllll} 
Yes & 91 & 12.1 & 363 & 20.6 & 454 & 18.0 \\
No & 662 & 87.9 & 1403 & 79.4 & 2065 & 82.0 \\
Total & 753 & 100.0 & 1766 & 100.0 & 2519 & 100.0 \\
\hline
\end{tabular}

IMNCI Integrated management of childhood illnesses.
Medicines prescribed other than antibiotics included antimalarials, analgesics, haematinics, cough remedies, antacids. The proportion of those prescribed antimalarials was $54.2 \%$ (408/753) among those who were not prescribed antibiotics and 35.6\% (628/1766) among those who were prescribed antibiotics.

A total of 1109 (44.0\%) of patients were referred for laboratory investigations, 1007 (40.0\%) were tested for malaria, 909 (36.1\%) took the full blood count test, 9 $(0.4 \%)$ took the stool routine examination, and 146 $(5.8 \%)$ took the urine routine examination. $74.6 \%$ of those for whom no laboratory investigation was requested were prescribed with antibiotics. Also, $40.4 \%$ of those who received antibiotics were tested.

Results of the multivariable logistic regression analyses (Table 5) identified the following as significant nonclinical factors of antibiotic prescription: location of facility (municipality), age of patient and prescriber's professional category, years of practice, and training in IMNCI, Compared to prescribers who had practised for less than 3 years, those who had 6 to 9 years of practice experience and those who had practiced for 10 years or more had 3 times (AOR $=2.97 ; 95 \% \mathrm{CI}$ : 1.99-4.44) and 1.6 times $(\mathrm{AOR}=1.60 ; 95 \% \mathrm{CI}: 1.12-2.27)$ higher odds of prescribing antibiotics, respectively. There was no statistically significant difference between antibiotic prescription by clinicians with 3 to 5 years of practice experience and that by clinicians with less than 3 years of practice. Prescribers who had ever been trained on IMNCI had 2.3 times greater odds of prescribing antibiotics than those who had never been trained $(\mathrm{AOR}=$ 2.33; 95\% CI: 1.54-3.53). After adjusting for all the other covariates, children aged 5 years or above were $60 \%$ $(\mathrm{AOR}=0.40 ; 95 \% \mathrm{CI}: 0.32-0.51)$ less likely to be prescribed antibiotics than those under 5 . 
Table 5 Crude and adjusted logistic regression of factors associated with antibiotic prescribing

\begin{tabular}{|c|c|c|c|c|}
\hline & Crude OR (95\% Cl) & $p$-value & Adjusted OR (95\% Cl) & $p$-value \\
\hline \multicolumn{2}{|c|}{ Prescriber's Profession (Ref: Medical Doctor) } & $0.001 * * *$ & & $0.029 *$ \\
\hline Physician Assistant & $0.75(0.60,0.94)$ & & $0.83(0.58,1.20)$ & \\
\hline Nurse Prescriber & $1.55(1.06,2.27)$ & & $1.30(0.70,2.41)$ & \\
\hline Other & $0.98(0.44,2.19)$ & & $8.33(1.32,52.41)$ & \\
\hline \multicolumn{2}{|c|}{ Prescriber's years of practice (Ref: $<3$ ) } & $<0.001^{* * *}$ & & $<0.001^{* * *}$ \\
\hline $3-5$ & $1.28(0.98,1.67)$ & & $1.12(0.84,1.48)$ & \\
\hline $6-9$ & $1.63(1.15,2.31)$ & & $2.97(1.99,4.44)$ & \\
\hline$\geq 10$ & $2.15(1.50,3.06)$ & & $1.60(1.12,2.27)$ & \\
\hline \multicolumn{2}{|c|}{ Prescriber ever trained on IMNCI (Ref: No) } & $<0.001^{* * *}$ & & $<0.001 * * *$ \\
\hline Yes & $1.88(1.38,2.56)$ & & $2.33(1.54,3.53)$ & \\
\hline \multicolumn{2}{|l|}{ Municipality (Ref: Ga South) } & $<0.001^{* * *}$ & & $<0.001 * * *$ \\
\hline La Dade Kotopon & $0.64(0.49,0.84)$ & & $0.16(0.09,0.27)$ & \\
\hline La Nkwantanang Madina & $1.17(0.89,1.54)$ & & $0.88(0.56,1.40)$ & \\
\hline \multicolumn{2}{|l|}{ Sex of patient (Ref: Male) } & 0.235 & & 0.627 \\
\hline Female & $0.90(0.77,1.07)$ & & $1.05(0.87,1.27)$ & \\
\hline \multicolumn{2}{|c|}{ Age of patient in years (Ref: $<5$ ) } & $<0.001 * * *$ & & $<0.001^{* * *}$ \\
\hline$\geq 5$ & $0.28(0.23,0.34)$ & & $0.40(0.32,0.51)$ & \\
\hline
\end{tabular}

$P<0.05^{*}, p<0.01^{* *}, p<0.001^{* * *}$, significance levels; Cl Confidence Interval, OR Odds ratio, Ref Reference.

The clinical factors significantly associated with antibiotic prescription as identified from the multivariable logistic regression (Table 6) include laboratory investigation, symptoms including cough, dizziness, difficulty in swallowing, watery stool, and diagnoses including urinary tract infection, typhoid fever, and skin disease. Patients who presented with cough were 3.54 times more likely to be prescribed antibiotics than those who did not present with cough (AOR $=3.54 ; 95 \% \mathrm{CI}: 2.54-4.92$ ). Patients for whom laboratory investigations were requested were $29 \%$ (AOR $=0.71 ; 95 \%$ CI: $0.57-0.89$ ) less likely to be prescribed antibiotics than those for whom laboratory investigations were not requested. Sex of patient, symptoms including general body pains, nasal congestion and diagnoses including ARTI and pneumonia were not significant factors of antibiotic prescribing $(p<0.05)$.

The age-stratified analyses in both crude and adjusted models showed that prescriber training on IMNCI was not significantly associated with antibiotic prescription in patients under 5 years but significantly associated among patients who were 5 years or more (Table 7).

The most prevalent diagnosis among the patients was ARTI (Fig. 1). The diagnoses not found to be significantly associated with antibiotic prescription were malaria, diarrhoeal diseases, anaemia, ear infection, eye infection, enteritis, trauma and tonsillitis (Table 3).

The variance inflation factor (VIF) for the exposure variables in the model were all less than 10 (Table 8 ), as such none of the variables were considered collinear with any other.

\section{Discussion}

We aimed to determine the factors associated with antibiotic prescription for febrile outpatients. The major factors identified were prescriber's profession and years of practice, age of patient, presenting symptoms including cough, watery stool, dizziness, difficulty in swallowing, laboratory tests, diagnoses including typhoid fever, urinary tract infection and skin disease.

Other studies have identified acute bronchitis, fever, sputum, tonsillar exudate, patient gender, time spent during prescriber-patient interaction and type of insurance, smoking, rhinorrhoea, sore throat, cough as significant predictors of antibiotic prescription among different populations [27-29]. Others include use of laboratory tests, patient turnout, financing moderated prescribing, medical knowledge and clinical competency, and good clinical practice [30,31]. Although clinical factors such as symptoms and diagnoses are critical to the decision process for prescribing antibiotics they are rarely investigated for their influence on antibiotic prescription. We discuss our findings with an aim to addressing this gap.

A high prescription of antibiotics for febrile outpatients was observed in our study. The prevalence of prescribing antibiotics, which was $70.1 \%$ (95\% CI: $67.7-$ 72.4) was higher than was found among febrile outpatients in Zambia [32]. An important difference observed 
Table 6 Crude and adjusted logistic regression of factors associated with antibiotic prescribing

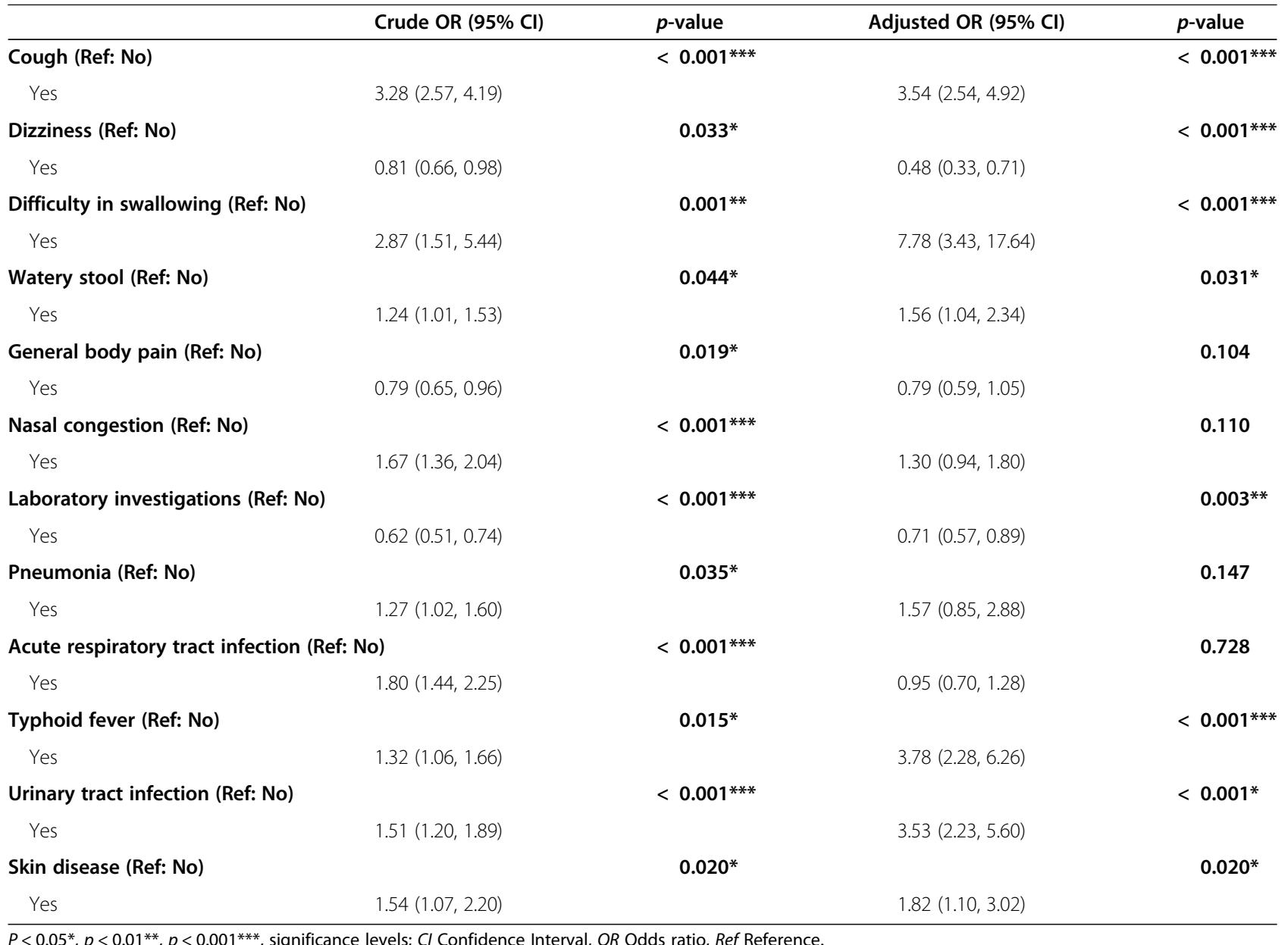

between the 2 studies which could explain the difference in prevalence is that a higher proportion of the febrile outpatients (74.6\%) underwent diagnostic testing in the Zambian study than in the present study (44\%). Studies in Uganda [33] and Cameroon [30] have shown that laboratory testing reduces the odds of antibiotic prescribing. Our findings showed that when laboratory investigations were requested prior to prescribing, patients were less likely to be prescribed with antibiotics. This was observed although the laboratory tests

Table 7 Crude and adjusted odds ratio of association between prescriber training on $\mathrm{IMNCl}$ and antibiotic prescribing

\begin{tabular}{|c|c|c|c|c|}
\hline Characteristic & COR & $p$-value & AOR & $p$-value \\
\hline \multicolumn{5}{|c|}{ Less than 5 years } \\
\hline \multicolumn{5}{|c|}{ Prescriber ever trained on IMNCI (Ref: No) } \\
\hline Yes & $1.36(0.86,2.13)$ & 0.189 & $2.05(0.99,4.25)$ & 0.055 \\
\hline
\end{tabular}

5 years or more

Prescriber ever trained on IMNCI (Ref: No)

$\begin{array}{lllll}\text { Yes } & 1.93(1.31,2.84) & 0.001 & 2.44(1.47,4.05) & 0.001\end{array}$

ABBREVIATION: AOR, Adjusted odds ratio, COR, Crude odds ratio, Ref, Reference requested did not include culture test or any nonmalaria point-of-care testing for infections. Advocating for the increased use of point-of-care tests for infections could improve the control of antibiotic prescribing.

The prevalence of antibiotic prescription in our study is higher than has been reported by other studies in Ghana, and other developing countries [11, 34, 35]. A critical difference between our study and these other studies is that only febrile patients were included in the current study. The higher use of antibiotics among febrile outpatients may not be justified since a majority of the infections targeted are mostly caused by viruses [36, 37]. It must be stated, however, that our study is limited in further evaluating this as we did not assess the appropriateness of the prescriptions.

Elsewhere, respiratory tract infection has been shown to be predictive of antibiotic prescription [30, 38, 39]. Other studies in Ghana also observed a high prescription of antibiotics for ARTI management at health facilities [40-42]. In the present study, the observation that neither ARTI nor pneumonia is significantly associated with antibiotic prescription seems progressive. 


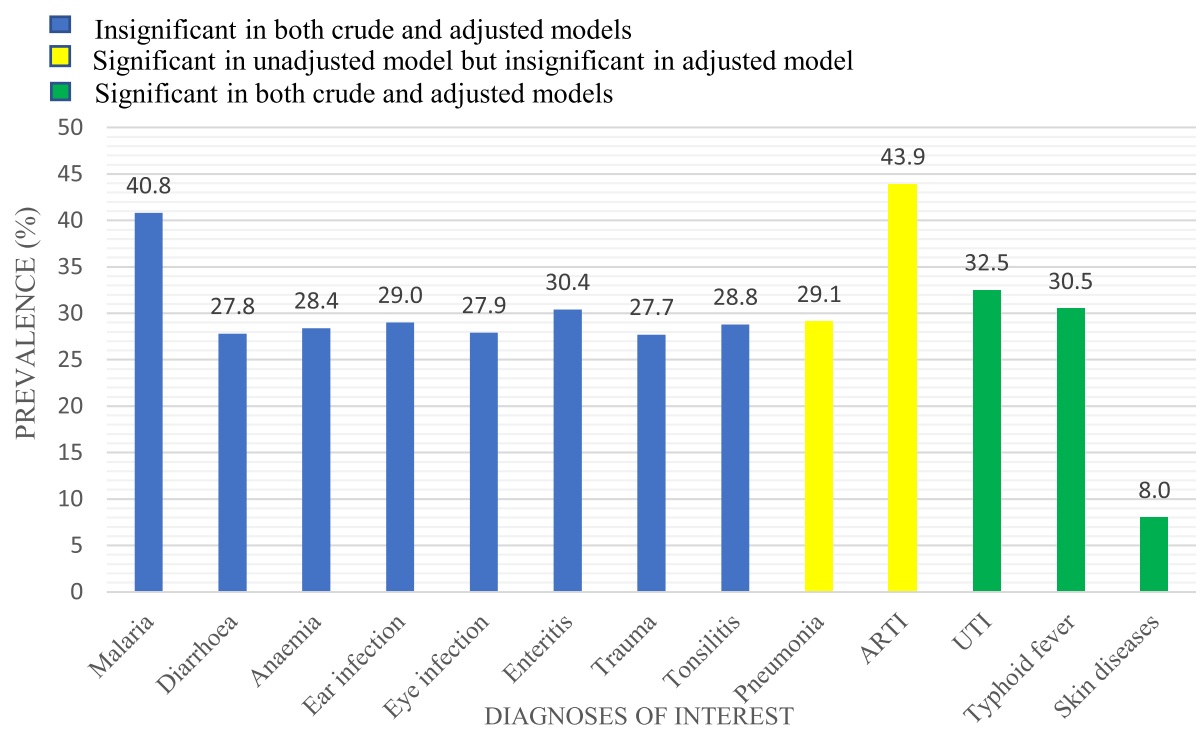

Fig. 1 Bar chart showing the prevalence of diagnoses of interest. Diagnoses of interest: all diagnoses which had a prevalence of at least $5 \%$ in the database. ARTI, Acute Respiratory Tract Infection; UTI, Urinary Tract Infection

The finding in our study is suggestive of prescribers appreciating that these diseases are more likely to be caused by viruses rather than bacteria [43, 44] or that using antibiotics to treat these diseases provides no clear benefit $[45,46]$. This understanding may be translated to the treatment of febrile illnesses at large since these principles apply generally but were not reflected in the findings. Cough is often associated with respiratory

Table 8 Variance Inflation Factor for independent variables in the adjusted logistic model

\begin{tabular}{ll}
\hline Variable & Variance Inflation Factor \\
\hline Profession & 1.5 \\
Years of Practice & 1.1 \\
Prescriber ever trained on IMNCl & 1.2 \\
Prescriber sex & 1.0 \\
Municipality & 1.6 \\
Age & 1.3 \\
Cough & 1.8 \\
Dizziness & 3.9 \\
Difficulty in swallowing & 1.1 \\
Watery stool & 3.3 \\
General body pain & 2.6 \\
Nasal congestion & 2.3 \\
Laboratory investigation & 1.1 \\
Pneumonia & 6.9 \\
Acute Respiratory Tract Infection & 1.6 \\
Typhoid fever & 4.6 \\
Urinary tract Infection & 2.9 \\
Skin infection & 1.1 \\
\hline
\end{tabular}

infection of one kind or the other. It seems paradoxical that it was found to be significantly associated with antibiotic prescription whilst ARTI was not. Accordingly, a patient who presents with cough is likely to be prescribed an antibiotic, irrespective of whether ARTI or pneumonia is diagnosed. This raises the question of whether prescribers treat symptoms rather than the diseases they diagnose. Another related observation is that patients who present with watery stool are likely to be treated with antibiotics though same cannot be said when diarrhoea is diagnosed. Further studies are required to investigate this practice.

That prescribers with more than 5 years of practice experience are more likely to prescribe antibiotics than those with less experience is at variance with a study conducted in Italy [47] but similar to another study in Canada [48]. Prescribers with fewer years of experience, who ordinarily may not have been promoted to the next level see themselves as amateurs and thus are more likely to adhere to guidelines and probably delay with prescribing antibiotics. However, those with more than 5 years' experience probably see themselves as experts, working as either a senior prescriber or above the rank of a senior prescriber, so may prescribe based on some experiences. The prescribing practices of more experienced prescribers must be targeted by antibiotic stewardship interventions.

Though inadequate training of prescribers has been shown to worsen antibiotic prescribing [49] we found that those not trained on IMNCI have lower odds of prescribing antibiotics. The subgroup analyses, however, showed that this was the case only among adult patients. Thus, our finding is consistent with findings 
from other studies that IMNCI training is beneficial for antibiotic prescription in children under 5 [50, 51]. IMNCI is child-focused preventative and curative care implemented in a way as to improve healthcare worker skills, the overall health system, and family and community health practices. It is noteworthy that IMNCI training is not implemented for the management of adult illnesses. It must be pointed out that one approach recommended by IMNCI is the active involvement of patients or caregivers in deciding on treatments [52]. This approach, however, has been suggested as influencing high antibiotic prescribing [29]. In countries such as Ghana where prescribers who attend to children tend to also see adults it may be useful to conduct further studies to investigate the residual influence of IMNCI training on antibiotic prescription in adults.

Regarding age, we found that patients aged 5 years or more had lower odds of being prescribed antibiotics. A similar observation was made in Cameroon [30]. Children under five, as a result of having less developed immune systems are more susceptible to infections than older people. Prescribers are more likely to manage illnesses of children in this age group with antibiotics than in older age groups. Also, the higher rate of mortality among children under 5 may condition prescribers to prefer erring cautiously by prescribing antibiotics given that treatments are usually done empirically. This is occasioned by the resource constraints of the health facilities and relatively expensive diagnostic tests. This trend is worrying considering that high antibiotic consumption in childhood has been linked with the development of metabolic diseases in later life [53].

We conducted a literature search on PubMed and Google scholar, and to the best of our knowledge this is the largest published study on antibiotic prescription in Ghana. The relatively large sample size allowed for the inclusion of several factors in the assessment. One limitation of this study is that the period of the data collection was short (3 months). As such, seasonal variations in antibiotic prescription was not accounted for. Another limitation of this study is the assumption that all documented actions were carried out. Similarly, all undocumented actions were assumed not to have been taken. This may have introduced misclassification bias but was considered more acceptable than direct observation which may have caused prescribers to vary their usual prescribing habit. Also, behavioural factors such as physician perception of patient desire, patient expectation and smoking were not assessed. Finally, findings of this study may not apply to febrile patients who were admitted due to disease severity.

\section{Conclusion}

The factors associated with antibiotic prescription for febrile outpatients were prescriber's profession and years of practice; age of patient; some presenting symptoms which included cough, watery stool, dizziness, difficulty in swallowing, laboratory tests; some diagnoses including typhoid fever, urinary tract infection and skin disease. In contrast, ARTI and pneumonia were not significantly associated with antibiotic prescription.

The rate of antibiotic prescription for febrile outpatients is high compared to practices from settings with similar burden of communicable diseases. To reduce this, advocacy for the increased use of laboratory testing prior to prescribing antibiotics is key. Also, more experienced prescribers and treatment for children under five should be targeted with interventions aimed at reducing antibiotic prescribing. IMNCI training appears to be counterproductive for controlling antibiotic prescribing in adults.

\section{Abbreviations}

ARTI: Acute Respiratory Tract Infection; EML: Essential Medicines List; IMNCl: Integrated Management of Neonatal and Childhood Illnesses; NHIS: National Health Insurance Scheme; OPD: Outpatient department; STG: Standard Treatment Guidelines; UTI: Urinary Tract Infection; WHO: World Health Organization

\section{Acknowledgements \\ We would like to acknowledge Dr. Adolf Kofi Awua of the Ghana Atomic Energy Commission, Prof. Kwame Ohene Buabeng of the Faculty of Pharmacy and Pharmaceutical Sciences, Kwame Nkrumah University of Science and Technology and Miss Lily Ogyiri of the School of Public Health, University of Ghana for reviewing and proof reading the manuscript.}

\section{Authors' contributions}

$H A B$ and $M M O$ conceptualised the study under the supervision of KAK. HAB assisted MMO in the analysis phase. Interpretation was done by MMO, HAB and KAK. All the authors reviewed and approved the final manuscript for publication.

\section{Funding}

German Academic Exchange Service Project provided funding for the original study-as part of funds for the PhD training program of the Corresponding author. They played no part in the conceptualisation, implementation and reporting of the study.

\section{Availability of data and materials}

The dataset is not publicly available. However, it can be accessed after a reasonable request has been sent to the corresponding author.

\section{Ethics approval and consent to participate}

No administrative permission was necessary to access and use the data/ records described because the corresponding author who is the principal investigator of this study was the principal investigator of the primary study that generated the dataset, and so provided the dataset for analyses of additional findings.

Consent for publication

Not applicable.

Competing interests

The authors declare that they have no competing interests. 


\section{Author details}

'Department of Epidemiology and Disease Control, School of Public Health, University of Ghana, Legon, Ghana. ${ }^{2}$ Department of Epidemiology, Noguchi Memorial Institute for Medical Research, University of Ghana, Legon, Ghana.

\section{Received: 9 April 2020 Accepted: 28 September 2020}

\section{Published online: 27 October 2020}

\section{References}

1. World Health Organization. Interventions and strategies to improve the use of antimicrobials in developing countries: a review, vol. 35; 2001.

2. Bell BG, Schellevis F, Stobberingh E, Goossens H, Pringle M. A systematic review and meta-analysis of the effects of antibiotic consumption on antibiotic resistance. BMC Infect Dis. 2014;14 https://doi.org/10.1186/14712334-14-13.

3. Klein EY, Van Boeckel TP, Martinez EM, Pant S, Gandra S, Levin SA, et al. Global increase and geographic convergence in antibiotic consumption between 2000 and 2015. Proc Natl Acad Sci. 2018;115:E3463-70.

4. World Health Organization, WHO Press. Antimicrobial resistance: global report on surveillance. Geneva: World Health Organization; 2014.

5. Hsu L-Y, Tan T-Y, Tam VH, Kwa A, Fisher DA, Koh T-H, et al. Surveillance and correlation of antibiotic prescription and resistance of gram-negative Bacteria in Singaporean hospitals. Antimicrob Agents Chemother. 2010;54: $1173-8$.

6. Llor C, Bjerrum L. Antimicrobial resistance: risk associated with antibiotic overuse and initiatives to reduce the problem. Therapeutic Adv Drug Saf. 2014;5:229-41

7. European Centre for Disease Prevention and Control. Annual Epidemiological report for 2017 - Antimicrobial consumption, vol. 23; 2017.

8. World Health Organization. WHO Report on Surveillance of Antibiotic Consumption. 2016-2018 Early implementation. Geneva; 2018.

9. Versporten A, Zarb P, Caniaux I, Gros M-F, Drapier N, Miller M, et al. Antimicrobial consumption and resistance in adult hospital inpatients in 53 countries: results of an internet-based global point prevalence survey. Lancet Glob Health. 2018:6:e619-29.

10. Vialle-Valentin CE, LeCates RF, Zhang F, Desta AT, Ross-Degnan D. Predictors of antibiotic use in African communities: evidence from medicines household surveys in five countries. Trop Med Int Health. 2012;17(2):211-22.

11. Labi A-K, Obeng-Nkrumah N, Nartey ET, Bjerrum S, Adu-Aryee NA, OforiAdjei YA, et al. Antibiotic use in a tertiary healthcare facility in Ghana: a point prevalence survey. Antimicrob Resist Infect Control. 2018;7 https://doi. org/10.1186/s13756-018-0299-z.

12. Sumaila A-N, Tabong PT-N. Rational prescribing of antibiotics in children under 5 years with upper respiratory tract infections in Kintampo municipal Hospital in Brong Ahafo Region of Ghana. BMC Res Notes. 2018;11 https:// doi.org/10.1186/s13104-018-3542-z.

13. Asante KP, Boamah EA, Abdulai MA, Buabeng KO, Mahama E, Dzabeng F, et al. Knowledge of antibiotic resistance and antibiotic prescription practices among prescribers in the Brong Ahafo region of Ghana; a cross-sectional study. BMC Health Serv Res. 2017;17 https://doi.org/10.1186/s12913-0172365-2.

14. Machowska A, Stålsby LC. Drivers of irrational use of antibiotics in Europe. Int J Environ Res Public Health. 2018;16:27.

15. Biezen R, Brijnath B, Grando D, Mazza D. Management of respiratory tract infections in young children - a qualitative study of primary care providers' perspectives. NPJ Prim Care Respir Med. 2017;27 https://doi.org/10.1038/ s41533-017-0018-x.

16. Cabral C, Horwood J, Hay AD, Lucas PJ. How communication affects prescription decisions in consultations for acute illness in children: a systematic review and meta-ethnography. BMC Fam Pract. 2014;15 https:// doi.org/10.1186/1471-2296-15-63.

17. World Health Organization. WHO Global Strategy for Containment of Antimicrobial Resistance, vol. 105; 2001.

18. Ministry of Health, Ministry of Food and Agriculture, Ministry of Environment, Science, Technology and Innovation, Ministry of Fisheries and Aquaculture Development. Policy on Antimicrobial Use and Resistance for Ghana. 1st ed; 2017.

19. Lopez-Vazquez P, Vazquez-Lago JM, Figueiras A. Misprescription of antibiotics in primary care: a critical systematic review of its determinants. J Eval Clin Pract. 2012;18:473-84.
20. Centre for Clinical Practice at NICE. National Institute for Health and Care Excellence: Clinical Guidelines. UK: National Institute for Health and Care Excellence; 2008.

21. McDonagh MS, Peterson K, Winthrop K, Cantor A, Lazur BH, Buckley DI. Interventions to reduce inappropriate prescribing of antibiotics for acute respiratory tract infections: summary and update of a systematic review. J Int Med Res. 2018:46:3337-57.

22. Bonful HA. SMS intervention and prescriber adherence to uncomplicated malaria case management guidelines in three municipalities in the Greater Accra region of Ghana: University of Ghana; 2017. http://ugspace.ug.edu.gh/ handle/123456789/25632.

23. World Health Organization, Global Malaria Programme. Guidelines for the treatment of malaria. 2015. http://www.ncbi.n/m.nih.gov/books/NBK294440/. Accessed 21 Jul 2020.

24. Ministry of Health, Ghana. Standard Treatment Guidelines, 2017. Ghana: National Drugs Programme; 2017.

25. StataCorp. Statistical Software: Release 14. College Station: StataCorp LP; 2015

26. WHO Collaborating Centre for Drug Statistics Methodology. Guidelines for ATC classification and DDD assignment 2013. Oslo; 2012.

27. Imanpour S, Nwaiwu O, McMaughan DK, DeSalvo B, Bashir A. Factors associated with antibiotic prescriptions for the viral origin diseases in officebased practices, 2006-2012. JRSM Open. 2017:8:2054270417717668.

28. Saliba-Gustafsson EA, Dunberger Hampton A, Zarb P, Orsini N, Borg MA, Stålsby LC. Factors associated with antibiotic prescribing in patients with acute respiratory tract complaints in Malta: a 1-year repeated cross-sectional surveillance study. BMJ Open. 2019;9 https://doi.org/10.1136/bmjopen-2019032704

29. McKay R, Mah A, Law MR, McGrail K, Patrick DM. Systematic review of factors associated with antibiotic prescribing for respiratory tract infections. Antimicrob Agents Chemother. 2016;60:4106-18.

30. Chem ED, Anong DN, Akoachere J-FKT. Prescribing patterns and associated factors of antibiotic prescription in primary health care facilities of Kumbo east and Kumbo west health districts. North West Cameroon. PLoS One. 2018;13:e0193353.

31. Lee T-H, Wong JG, Lye DC, Chen MI, Loh WW, Leo Y-S, et al. Medical and psychosocial factors associated with antibiotic prescribing in primary care: survey questionnaire and factor analysis. Br J Gen Pract. 2017;67:e168-77.

32. Ndhlovu M, Nkhama E, Miller JM, Hamer DH. Antibiotic prescribing practices for patients with fever in the transition from presumptive treatment of malaria to 'confirm and treat' in Zambia: a cross-sectional study. Tropical Med Int Health. 2015;20:1696-706.

33. Batwala V, Magnussen P, Nuwaha F. Antibiotic use among patients with febrile illness in a low malaria endemicity setting in Uganda. Malar J. 2011; 10:377.

34. Holloway KA, Ivanovska V, Wagner AK, Vialle-Valentin C, Ross-Degnan D. Have we improved use of medicines in developing and transitional countries and do we know how to? Two decades of evidence. Tropical Med Int Health. 2013;18:656-64.

35. Ofori-Asenso R, Brhlikova P, Pollock AM. Prescribing indicators at primary health care centers within the WHO African region: a systematic analysis (1995-2015). BMC Public Health. 2016;16 https://doi.org/10.1186/s12889016-3428-8.

36. Malm KL. Acute febrile illness: the role of respiratory synctial virus and malaria in an urban peadiatric population in Ghana. Legon: University of Ghana; 2011.

37. D'Acremont V, Kilowoko M, Kyungu E, Philipina S, Sangu W, Kahama-Maro J, et al. Beyond malaria - causes of fever in outpatient Tanzanian children. N Engl J Med. 2014;370:809-17.

38. O'Brien K, Bellis TW, Kelson M, Hood K, Butler CC, Edwards A. Clinical predictors of antibiotic prescribing for acutely ill children in primary care: an observational study. Br J Gen Pract. 2015;65:e585-92.

39. Anderson $\mathrm{H}$, Vuillermin $\mathrm{P}$, Jachno $\mathrm{K}$, Allen $\mathrm{KJ}$, Tang ML, Collier F, et al. Prevalence and determinants of antibiotic exposure in infants: a populationderived Australian birth cohort study: antibiotic use in Australian infants. J Paediatr Child Health. 2017:53:942-9.

40. Opoku MM. Assessment of antibiotics prescribing practices at the Sunyani municipal hospital in 2015: Thesis: University of Ghana; 2017. http://ugspace. ug.edu.gh/handle/123456789/23711. Accessed 12 Nov 2019.

41. Duah NA. Prescription practices and patterns of antibiotics used in children attending the Princess Marie Louise Children's hospital: Thesis: University of 
Ghana; 2018. http://ugspace.ug.edu.gh/handle/123456789/25873. Accessed 12 Nov 2019.

42. Anamuah-Mensah M. A survey of antibiotic usage at holy trinity medical Centre. 2009. http://ir.knust.edu.gh:8080/handle/123456789/377. Accessed 12 Nov 2019.

43. Johnstone J, Majumdar SR, Fox JD, Marrie TJ. Viral infection in adults hospitalized with community-acquired pneumonia: prevalence, pathogens, and presentation. CHEST. 2008;134:1141-8.

44. Marcos MA, Camps M, Pumarola T, Martinez JA, Martinez E, Mensa J, et al. The role of viruses in the aetiology of community-acquired pneumonia in adults. Antivir Ther. 2006;9:351-9.

45. Woodhead M, Blasi F, Ewig S, Garau J, Huchon G, leven M, et al. Guidelines for the management of adult lower respiratory tract infections - full version. Clin Microbiol Infect. 2011;17:E1-59.

46. Smith SM, Fahey T, Smucny J, Becker LA. Antibiotics for acute bronchitis Cochrane Database Syst Rev. 2014;3. https://doi.org/10.1002/14651858. CD000245.pub3.

47. Di Martino M, Lallo A, Kirchmayer U, Davoli M, Fusco D. Prevalence of antibiotic prescription in pediatric outpatients in Italy: the role of local health districts and primary care physicians in determining variation. A multilevel design for healthcare decision support. BMC Public Health. 2017: $17 \mathrm{https}: / /$ doi.org/10.1186/s12889-017-4905-4.

48. Cadieux G, Tamblyn R, Dauphinee D, Libman M. Predictors of inappropriate antibiotic prescribing among primary care physicians. Can Med Assoc J. 2007; $177: 877-83$

49. Calbo E, Álvarez-Rocha L, Gudiol F, Pasquau J. A review of the factors influencing antimicrobial prescribing. Enferm Infecc Microbiol Clin. 2013;31: $12-5$.

50. Gouws E, Bryce J, Habicht J-P, Amaral J, Pariyo G, Schellenberg JA, et al. Improving antimicrobial use among health workers in first-level facilities: results from the Multi-Country Evaluation of the Integrated Management of Childhood Illness strategy. Bull World Health Organ. 2004;7:509-15.

51. El Mahalli AA, Akl OA. Effect of adopting integrated management of childhood illness guidelines on drug use at a primary health care center: a case study from Egypt. J Fam Community Med. 2011;18:118-23.

52. Victora CG, Adam T, Bryce J, Evans DB. Integrated Management of the Sick Child. In: Disease Control Priorities in Developing Countries. 2nd ed. Washington DC: The World Bank and Oxford University Press; 2006. p. 1177-92.

53. Mensah KB, Ansah C. Irrational use of antibiotics and the risk of diabetes in Ghana. Ghana Med J. 2016;50:107-14.

\section{Publisher's Note}

Springer Nature remains neutral with regard to jurisdictional claims in published maps and institutional affiliations.

Ready to submit your research? Choose BMC and benefit from:

- fast, convenient online submission

- thorough peer review by experienced researchers in your field

- rapid publication on acceptance

- support for research data, including large and complex data types

- gold Open Access which fosters wider collaboration and increased citations

- maximum visibility for your research: over $100 \mathrm{M}$ website views per year

At $\mathrm{BMC}$, research is always in progress.

Learn more biomedcentral.com/submissions 